Article

\title{
Fungal Pretreatment of Willow Sawdust with Abortiporus biennis for Anaerobic Digestion: Impact of an External Nitrogen Source
}

\author{
Maria Alexandropoulou ${ }^{1,2}$, Georgia Antonopoulou ${ }^{1, *}$, Ioanna Ntaikou 1 \\ and Gerasimos Lyberatos 1,2 \\ 1 Institute of Chemical Engineering Sciences, Stadiou, Platani, GR 26504 Patras, Greece; \\ alexandropouloumaria@gmail.com (M.A.); iwntaikou@iceht.forth.gr (I.N.) \\ 2 School of Chemical Engineering, National Technical University of Athens, GR 15780 Athens, Greece; \\ lyberatos@chemeng.ntua.gr \\ * Correspondence: geogant@chemeng.upatras.gr; Tel.: +30-261-096-5318
}

Academic Editors: Dimitrios Komilis and Vincenzo Torretta Received: 22 December 2016; Accepted: 13 January 2017; Published: 17 January 2017

\begin{abstract}
In this study the effect of nitrogen $(\mathrm{N})$ supplementation in the fungal pretreatment of willow sawdust (WSD) via the white rot fungus Abortiporus biennis (A. biennis) was studied in terms of the fractionation of lignocellulosic biomass and biochemical methane potential (BMP). Thus, different external nitrogen sources (yeast extract (YE), urea (UR), and ammonium nitrate (AN)) at different ratios $(\mathrm{N} / \mathrm{C}$ of $1 / 250$ and $1 / 50)$ were added and the effect of the above parameters on the chemical composition of WSD during solid-state fermentation (SSF) experiments with A. biennis was assessed and compared to the experiment of fungal pretreatment without $\mathrm{N}$ supplementation ( $\mathrm{N} / \mathrm{C}$ was $1 / 500$, control experiment). The results indicated that the addition of an external nitrogen source did not facilitate delignification, regardless of the type of nitrogen source and the ratio of N/C used. On the other hand, enhanced cellulose uptake was observed. Samples of the 28th day of cultivation, with and without $\mathrm{N}$ supplementation, were used for BMP tests, where a reduction in methane yield was observed, compared to the control experiment. In addition, a combination of fungal with alkali ( $20 \% \mathrm{NaOH} w / w$ dry mass) pretreatment was performed in order to assess the effect of combined pretreatment on the lignocellulosic content and the BMP.
\end{abstract}

Keywords: fungal pretreatment; Abortiporus biennis; nitrogen source; delignification; willow sawdust; anaerobic digestion; methane; combined pretreatment; fungal and alkali pretreatment

\section{Introduction}

Biofuel production has become an imperative need for future energy use due to the rapid depletion of the fossil fuels, and climate change, such as global warming and environmental pollution. Anaerobic digestion (AD) of lignocellulosic residues towards biogas production seems to be the most promising process for biofuels generation [1]. Its advantage compared to other biofuels is that methane gas could be used directly for heat and electricity.

Lignocellulosic biomass is renewable, widely available, rich in complex carbohydrates $(55 \%-75 \%$ in total solids (TS)), and not competitive with food or feed crops [2]. However, the biotransformation to methane is not an easy task, due to the complex structure of lignocellulose (cellulose is embedded in an amorphous matrix of hemicellulose and lignin) and the low biodegradability of lignin under anaerobic conditions [2]. Thus, a variety of physical, chemical, and biological pretreatment methods have been proposed so far, in order to break down the lignin seal and to enhance AD efficiency and biogas production [3]. 
During physico-chemical pretreatment, the use of chemicals or extreme conditions of temperature or pressure are often needed, while depending on the conditions applied, inhibitory compounds are also produced in different amounts [4,5]. In this respect, the biological pretreatment appears as an environmental friendly alternative. It is based on the special abilities of a small group of filamentous fungi, known as white-rot fungi (WRF), capable of degrading lignin, by using a set of extracellular ligninolytic enzymes, without producing inhibitors [6]. The ligninolytic system of WRF involves lignin peroxidase (LiP or "ligninase"), manganese peroxidase (MnP), and laccase (orphenoloxidases). It should be emphasized that all the above enzymes are not produced from all WRFs; in some cases WRF could produce only one of them $[7,8]$. Strains of WRF have the ability to selectively degrade lignin from lignocellulosic substrates, while exhibiting low cellulose uptake efficiency, using mostly hemicellulose as a carbon source [2,6]. Selective delignification (degradation of lignin over cellulose) reduces the recalcitrance of lignocellulosic biomass, thus enhancing methane production, especially in the case of feedstocks with very low initial biodegradability [2]. Amirta et al. [9] observed a six-fold increase in $\mathrm{CH}_{4}$ generation for fungi-pretreated Japanese cedar wood, compared to untreated wood. On the other hand, high holocellulose losses could lead to a lower methane potential compared to the respective of the untreated substrate $[6,10]$ and, thus, fungus selection is one of the key points for an efficient biological pretreatment.

The other crucial parameter is the optimization of the cultivation conditions, including inoculation, moisture content, temperature, aeration, particle size of biomass and supplements, during the solid-state fermentation (SSF) of biomass [11,12]. Regarding supplements, the effect of nitrogen on the fungal pretreatment has been rarely evaluated. It is reported that even under nitrogen-starvation conditions, delignification could be achieved from the majority of WRF [2]. However, the role of WRF during SSF experiments could not be clearly assessed, since, in the literature, contradicting views have been reported. According to Wan et al. [11], nitrogen supplementation can inhibit delignification, while stimulating fungal growth and sugar consumption, whereas other studies have reported a positive effect on lignolytic enzyme production [13] depending also by the specific nitrogen source used [14,15]. Moreover, under a high nitrogen concentration, a low lignin selectivity was observed and this could be associated with the stimulation of cellulose degradation [2]. Mikiashvili et al. [16], who evaluated the impact of different nitrogen sources on oxidative enzyme production, expressed as enzymatic activity of laccasse, $\mathrm{MnP}$, and peroxidase, by new isolates of Trametes versicolor (T. versicolor), observed an enhanced ligninolytic enzyme accumulation in the medium. This was caused by the increased fungal biomass production. In addition, it was found that all organic nitrogen sources tested favored lacasse, $\mathrm{MnP}$ and peroxidase accumulation by T. versicolor 775 [16]. However, the higher enzymatic production could not be related to a higher delignification efficiency.

The main drawback of fungal pretreatment could be the extended time needed to improve lignocellulosic's digestibility, which can be as long as $4-8$ weeks [17]. The combination of fungal pre-treatment with a physicochemical pre-treatment method might be considered as an alternative pre-treatment strategy to reduce the time needed. Such a combined pre-treatment can cause fractionation of lignocellulosics, by enhancing cellulose digestibility, reducing production of inhibitors, and improving delignification [18]. Positive results have been reported for fungal treatment followed by $\mathrm{NaOH}$, acid, or steam explosion, causing an increase in dry mass loss, as well as enhanced lignin and holocellulose degradation efficiency [6,12].

In our previous study, fungal pre-treatment of willow sawdust (WSD) via the WRF Leiotrametes menziesii and Abortiporus biennis was studied and the effect on fractionation of lignocellulosic biomass and on the biochemical methane potential (BMP) was evaluated [6]. A. biennis was found to be more attractive for biological pretreatment of WSD, exhibiting high delignification and, simultaneously, very low cellulose uptake efficiency, resulting in a BMP increase by $43 \%$ (from $95.5 \pm 4.3$ for the untreated WSD to $136.7 \pm 1.1 \mathrm{~L} \cdot \mathrm{CH}_{4} / \mathrm{kg}$ TS for fungi-pre-treated WSD) [6]. The aim of the present study was to assess, for the first time, the effect of nitrogen supplementation (different $\mathrm{N} / \mathrm{C}$ ratios) and external nitrogen source (yeast extract (YE), urea (UR), and ammonium nitrate (AN)) on the fractionation 
of lignocellulosic biomass of WSD during SSF experiments (0-28 day of cultivation) with A. biennis. In addition, the effect of these parameters on the BMP of fungi-pre-treated WSD is studied for the first time. Finally, the combination of fungal pre-treatment with alkali pre-treatment was studied and its effect on the lignocellulosic content and AD efficiency of WSD was also evaluated since, in our previous study, such a combination of pretreatment methods led to a $115 \%$ increase of the BMP when compared with the BMP of the raw untreated substrate [6].

\section{Materials and Methods}

\subsection{WSD Used}

WSD used in this study was collected in the region of Athens, Greece and the procedure of milling, sieving, and air drying that was followed is described in Alexandropoulou et al. [6]. The main characteristics of the substrate used are presented in Table 1 . The ratio of N/C was $1 / 500$ corresponding to $2 \mathrm{mg} \cdot \mathrm{N} / \mathrm{gC}$.

Table 1. The main characteristics of WSD used in this study (based on Alexandropoulou et al. [6]).

\begin{tabular}{cc}
\hline Characteristic & Value \\
\hline$\%$ TS $^{\mathrm{a}}(w / w)$ & $94.53 \pm 1.14$ \\
$\%$ VS $^{\mathrm{b}}(w / w)$ & $88.92 \pm 1.21$ \\
$\%$ Cellulose $(w / w)$ & $35.59 \pm 0.91$ \\
$\%$ Hemicellulose $(w / w)$ & $21.50 \pm 0.89$ \\
\% Lignin $(w / w)$ & $28.71 \pm 0.23$ \\
$\%$ Extractives $(w / w)$ & $3.00 \pm 0.13$ \\
$\%$ Ash $(w / w)$ & $5.91 \pm 1.62$ \\
\% Proteins $(w / w)$ & $0.69 \pm 0.14$ \\
$\%$ Total organic carbon $(w / w)$ & $51.12 \pm 0.93$ \\
\hline a TS: total solids; ${ }^{\mathrm{b}}$ VS: volatile solids.
\end{tabular}

\subsection{Pretreatment Conditions}

\subsubsection{Fungal Strains}

A. biennis strain BRFM 1215 was kindly provided by the CIRM-CF fungal collection (Banque de Ressources Fongiques de Marseille) on malt agar slants and were maintained at $4{ }^{\circ} \mathrm{C}$. Inoculation cultures were prepared as described in Alexandropoulou et al. [6] and the concentration of total suspended solids (TSS) and volatile suspended solids (VSS) of the fungal suspensions were $3.32 \pm 0.01$ and $3.26 \pm 0.01 \mathrm{~g} / \mathrm{L}$, respectively.

\subsubsection{Fungal Pretreatment: The Effect of External Nitrogen Source}

Seven sets of 10 identical SSF batch cultures were prepared with $6 \mathrm{~g}$ sterilized air-dried WSD in $250 \mathrm{~mL}$ Erlenmeyer flasks, according to the protocol described in Alexandropoulou et al. [6]. Briefly, $8 \mathrm{~mL}$ of mycelia suspension were aseptically inoculated in the flasks, where sterilized deionized water was also added, in order to achieve $80 \%$ humidity. The effect of the nitrogen source was studied by six sets of SSF experiments, with three different organic and inorganic nitrogen sources (yeast extract (YE), urea (UR) and ammonium nitrate (AN)) at two different concentrations: the ratio of $\mathrm{N} / \mathrm{C}$ was set to: (a) $1 / 250$ corresponding to $4 \mathrm{mg} \mathrm{N} / \mathrm{gC}$ (low nitrogen concentration or low $\mathrm{N}$ ) which was two times higher than WSD without $\mathrm{N}$ supplementation; and (b) $1 / 50$ corresponding to $20 \mathrm{mg}$ $\mathrm{N} / \mathrm{gC}$ (high nitrogen concentration, or high $\mathrm{N}$ ) which was 10-fold higher than the WSD without $\mathrm{N}$ supplementation. One set of 10 Erlenmeyer flasks with $6 \mathrm{~g}$ sterilized air-dried WSD with inoculum, but without any nutrients addition were also prepared and used as control. Subsequently, the 70 flasks were plugged with hydrophobic cotton and were incubated at $27 \pm 0.5^{\circ} \mathrm{C}$. In each sampling at 7,14 , 21 , and 28 day, two cultures were removed and forwarded for analysis, whereas samples from the 28th 
day of cultivation were used for assessing the methane potential, through BMP tests, in batch reactors, as described below.

\subsubsection{Combination of Fungal with Alkali Pre-treatment}

The fungi-pre-treated samples after 28 day of cultivation were subjected to alkaline pre-treatment, using $\mathrm{NaOH} 20 \% w / w$ dry mass at $80{ }^{\circ} \mathrm{C}$ for $24 \mathrm{~h}$, with a solids load of $5 \% w / v$ (5 g solids in $100 \mathrm{~mL}$ solution). For comparison purposes, only alkaline treatment at the same conditions $(\mathrm{NaOH} 20 \% w / w$ dry mass at $80{ }^{\circ} \mathrm{C}$ for $24 \mathrm{~h}$ ) was performed using raw WSD. All experiments were performed in duplicate. After pre-treatment, the samples were analysed and their methane potential was assessed through BMP experiments.

\subsection{BMP Tests}

BMP experiments were performed for (a) fungi-pre-treated samples after 28 day of cultivation, supplemented with different external $\mathrm{N}$ sources at different N/C ratios; (b) for alkaline pretreated WSD samples; and (c) for combined alkaline and fungi-pre-treated samples after 28 day of cultivation, supplemented with different $\mathrm{N}$ sources at different $\mathrm{N} / \mathrm{C}$ ratios. BMP experiments were carried out in duplicate at $35{ }^{\circ} \mathrm{C}$ in serum bottles of $160 \mathrm{~mL}$, according to the modified protocol of Owen and Chynoweth [19] as described in Alexandropoulou et al. [6]. Anaerobic sludge from the anaerobic digester of the Metamorphosis, Athens wastewater treatment plant, operating at steady state at an hydraulic retention time of 15 day, was used as inoculum. The main characteristics of the sludge were: pH: 7.33, TSS: $38.44 \pm 1.24 \mathrm{~g} / \mathrm{L}$ and VSS: $18.38 \pm 0.89 \mathrm{~g} / \mathrm{L}$. Briefly, for fungi-pre-treated samples, $20 \mathrm{~mL}$ mixed anaerobic culture, $80 \mathrm{~mL}$ water and appropriate amounts of samples were added, in order to acquire $2 \mathrm{~g}$ VS/L, while for the alkali-pre-treated samples (alone or in combination with fungal pre-treatment), $20 \mathrm{~mL}$ of mixed anaerobic culture were seeded with $4 \mathrm{~mL}$ of the whole pre-treatment slurry (mixed liquor of the alkaline pre-treated feedstocks at a solids load of $5 \% w / v$ ) so as to obtain a final VS content in the vial of $2 \mathrm{~g} / \mathrm{L}$ and deionised water to a final volume of $100 \mathrm{~mL}$. The microbial culture was supplemented with $10 \mathrm{~mL} / \mathrm{L}$ of a $\left(\mathrm{NH}_{4}\right)_{2} \mathrm{HPO}_{4}(7.21 \mathrm{~g} / \mathrm{L})$ solution, $10 \mathrm{~mL} / \mathrm{L}$ of a $\mathrm{FeSO}_{4} \cdot 7 \mathrm{H}_{2} \mathrm{O}(0.7 \mathrm{~g} / \mathrm{L})$ solution, and $10 \mathrm{~mL} / \mathrm{L}$ of a trace metals solution [20]. Control experiments for checking the methanogenic biomass activity were carried out using glucose and cellulose. Blank experiments were also carried out in order to determine the background gas productivity of the inoculum. The content of the vials was gassed with a mixture of $\mathrm{N}_{2} / \mathrm{CO}_{2}(80 / 20)$ in order to secure anaerobic conditions. The vials were sealed with butyl rubber stoppers and aluminum crimps and total biogas, as well as methane production were monitored as a function of time via a syringe, according to Owen and Chynoweth [19].

\subsection{Analytical Methods and Procedures}

The analytical procedure for sample characterization in terms of lignocellulosic content is presented in Alexandropoulou et al. [6]. Briefly, raw samples were air-dried and then used for ethanol extraction [21] prior to analysis. Then the extractive free biomass was used to determine the structural carbohydrates and the lignin content, with a two-step acid hydrolysis method, according to the National Renewable Energy Laboratory (NREL)'s standard laboratory analytical procedure (LAP) for the determination of structural carbohydrates in biomass [22]. Detection and quantification of sugar monomers (glucose, xylose and arabinose) were performed with an High Performance Liquid Chromatography (Dionex Ultimate 3000, Sunnyvale, CA, USA) equipped with a Refractive Index Detector(HPLC-RI (Shodex RI 101)) with an Aminex HPX-87H column (Biorad Laboratories, Philadelphia, PA, USA) at $60^{\circ} \mathrm{C}$ and a Cation $\mathrm{H}$ micro-guard cartridge (Biorad Laboratories) using $\mathrm{H}_{2} \mathrm{SO}_{4} 0.006 \mathrm{~N}$ as an eluent at a flow rate of $0.7 \mathrm{~mL} / \mathrm{min}$. Acid-soluble and -insoluble (Klason) lignin content was calculated according to NREL's standard laboratory analytical procedure [22].

For the characterization of the fungi-pre-treated samples, supplemented or not with external $\mathrm{N}$ sources, the biomass was suspended in $80 \mathrm{~mL}$ deionized water for $1 \mathrm{~h}$ at $30^{\circ} \mathrm{C}$ and the liquid and solid 
fractions were separated, through filtering with $0.7 \mu \mathrm{m}$ filters, while for the samples after the alkaline pre-treatment, only separation of liquid and solid fractions was performed, via filtration. The solid fractions were washed with water, air-dried, and characterized as described above for the raw samples, but without performing the extraction process prior to characterization. Since only the solid fraction obtained after pretreatment was used for chemical composition analysis, the solid material recovery due to the loss of weight was taken into account.

The liquid fractions were used for soluble carbohydrates' content determination, according to Joseffson [23], while the analysis of phenolic compounds was conducted using the Folin and Ciocalteu method, using a syringic acid standard solution for calibration [24]. The measurements of TS, volatile solids (VS), TSS, and VSS were carried out according to Standard Methods [25]. Raw and extractive-free samples were also used to determine total kjeldahl nitrogen (TKN) and total organic carbon (TOC) (according to standard methods [25]). The crude protein content was determined by multiplying TKN by a factor of 6.25 .

The methane content of the produced biogas was quantified with a gas chromatograph (SRI 8610c MG\#1with two columns in series: molecular sieve column, $6 \mathrm{ft}$, OD 1/8 inch, ID 2.1mm and silica gel column, $6 \mathrm{ft}$, OD $1 / 8$ inch) equipped with a thermal conductivity detector and a packed column. The carrier gas was helium. The injector, column, and detector temperatures were set at $90{ }^{\circ} \mathrm{C}, 35^{\circ} \mathrm{C}$, and $100{ }^{\circ} \mathrm{C}$, respectively.

\section{Results and Discussion}

\subsection{Effect of Nitrogen Supplementation on the Lignocellulosic Content during Fungal Pretreatment}

In Figures 1-3 the reduction of lignin, cellulose, and hemicellulose content of WSD, as well as the material recovery during pretreatment with A. biennis and supplementation with YE, UR, or AN are presented. The cultivation period, as also described above, was 28 day, with weekly sampling, whereas two different concentrations of each nitrogen source were used in order to achieve a two-fold and ten-fold increase of the initial ratio of N/C of the substrate.

(a)
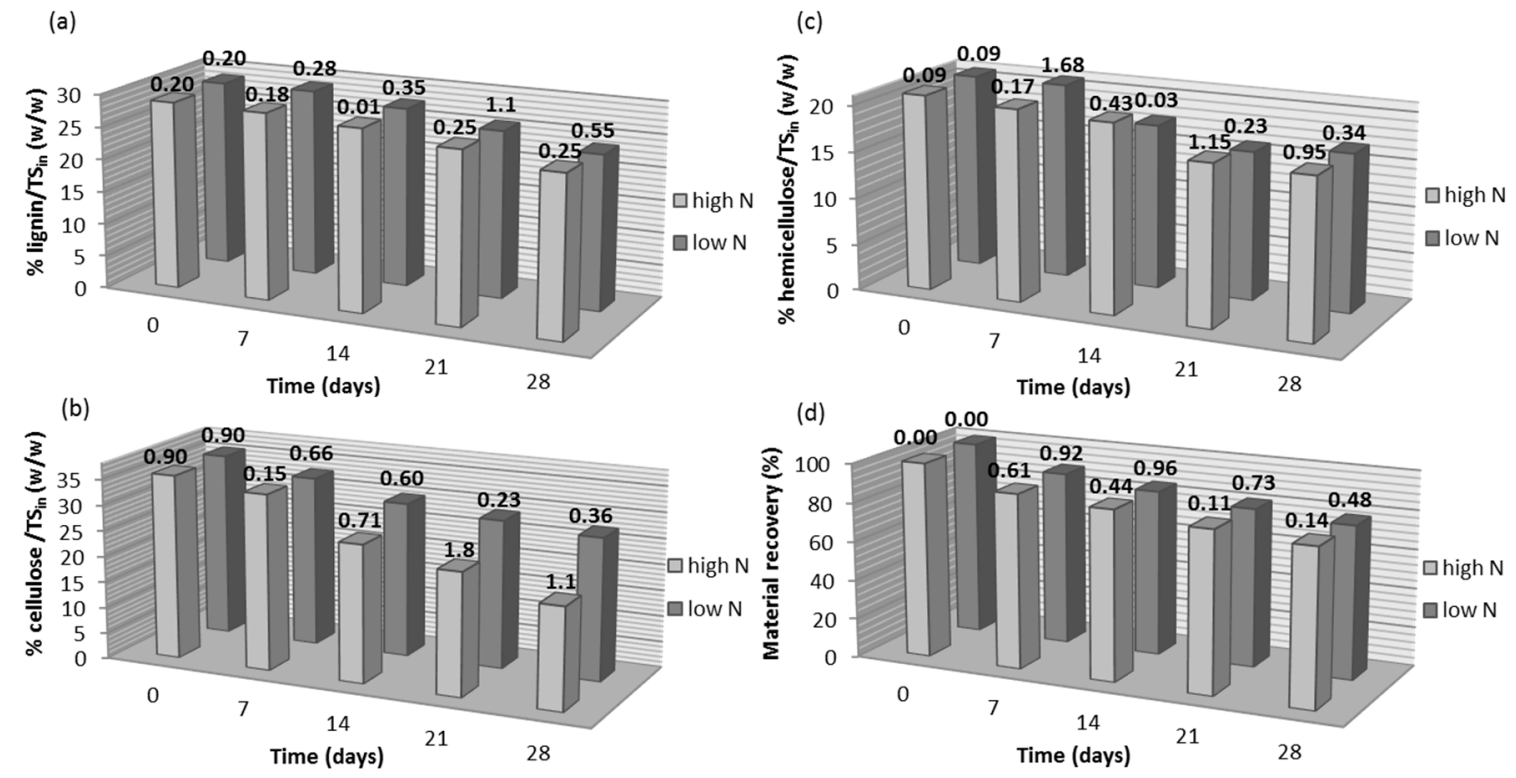

Figure 1. Changes in the relative ratios of: (a) lignin; (b) cellulose; and (c) hemicellulose to the initial total solids of WSD; and (d) material recovery, during fungal pretreatment with the addition of yeast extract as external nitrogen source at high and low $\mathrm{N}$ concentration. Numbers above the bars indicate the standard deviation of duplicates. 
(a)

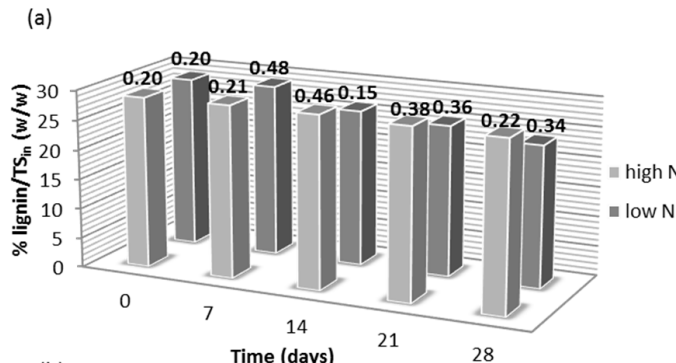

(c)

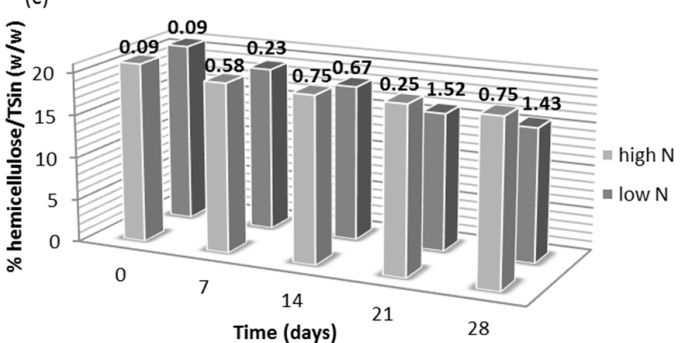

(d)

Time (days)
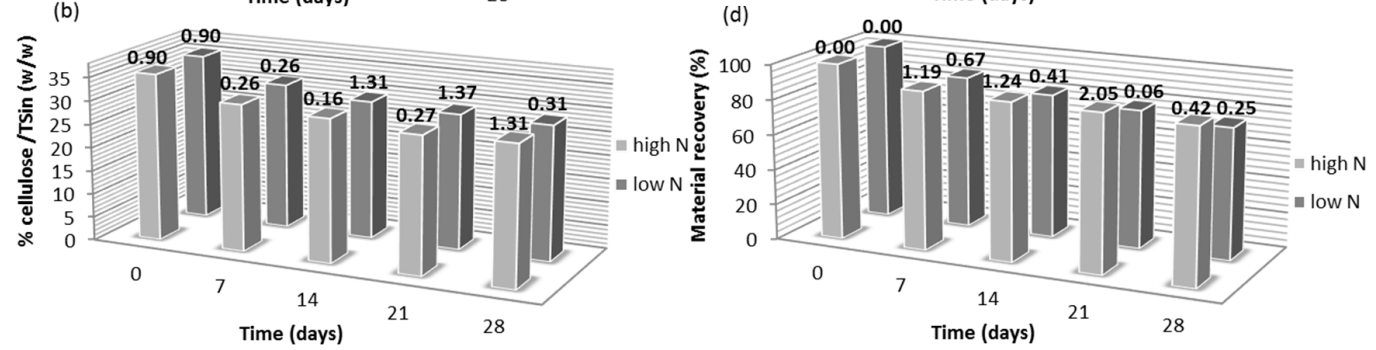

Figure 2. Changes in the relative ratios of: (a) lignin; (b) cellulose; and (c) hemicellulose to the initial total solids of WSD; and (d) material recovery, during fungal pretreatment with the addition of urea as external nitrogen source at high and low $\mathrm{N}$ concentration. Numbers above the bars indicate the standard deviation of duplicates.
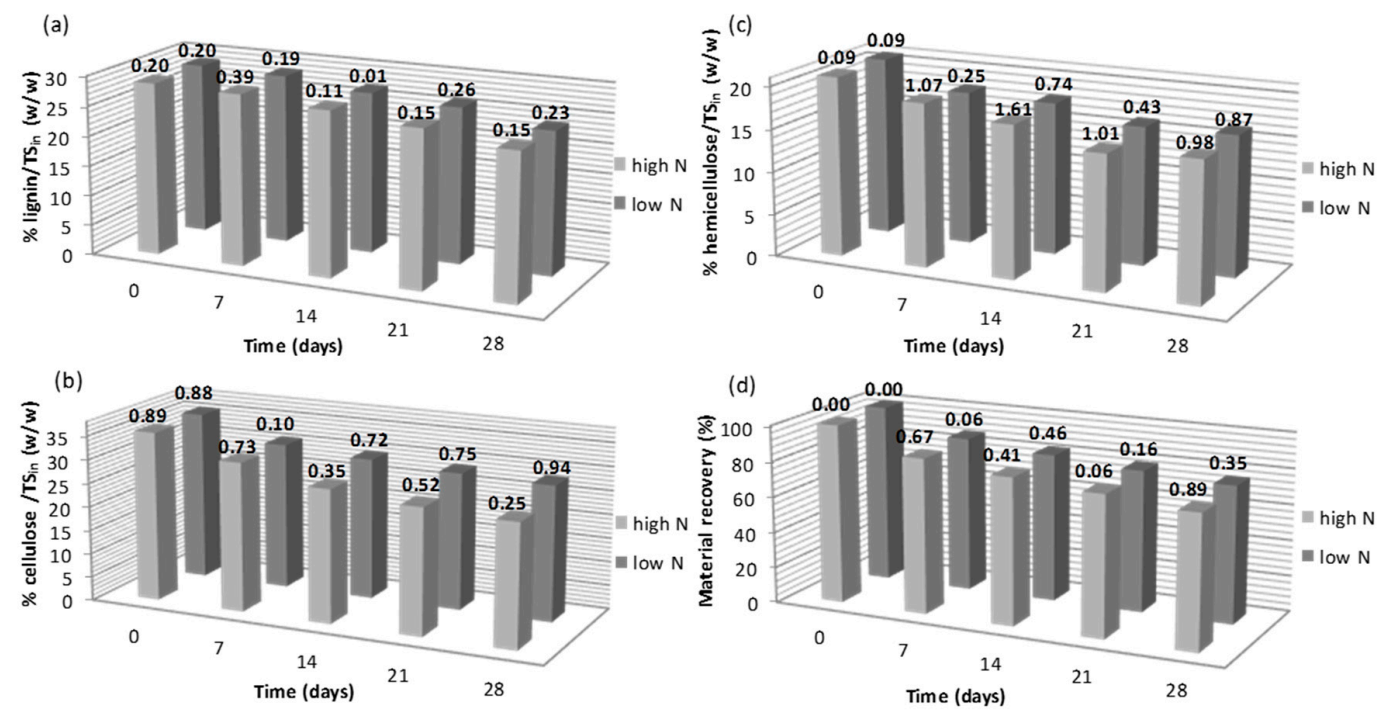

Figure 3. Changes in the relative ratios of: (a) lignin; (b) cellulose; and (c) hemicellulose to the initial total solids of WSD; and (d) material recovery, during fungal pretreatment with the addition of ammonium nitrate as external nitrogen source at high and low $\mathrm{N}$ concentration. Numbers above the bars indicate the standard deviation of duplicates.

The addition of an external nitrogen source in the cultures during fungal pretreatment does not seem to facilitate delignification of the current substrate, regardless of the type of nitrogen source and the ratio of N/C used. As shown in Figures 1a, 2a and 3a, the addition of all three types of external nitrogen source at both concentrations, except for the high concentration of urea addition $\left(\mathrm{UR}_{\text {high }}\right)$, led to similar delignification rates. The delignification process was, in all cases, comparable to that of the control experiment (Figure $4 \mathrm{a}$ ), leading to a final lignin content of $\sim 24 \%$ of $\mathrm{TS}_{\text {in }}$, at 28 days of cultivation. The delignification process was only differentiated in the case of $U_{\text {high }}$ (Figure 2a), for which the final lignin content at 28 day of cultivation was actually $4 \%$ higher than the respective control, i.e., $28.30 \% \pm 0.22 \%$ and $23.27 \% \pm 0.25 \%$, respectively. 

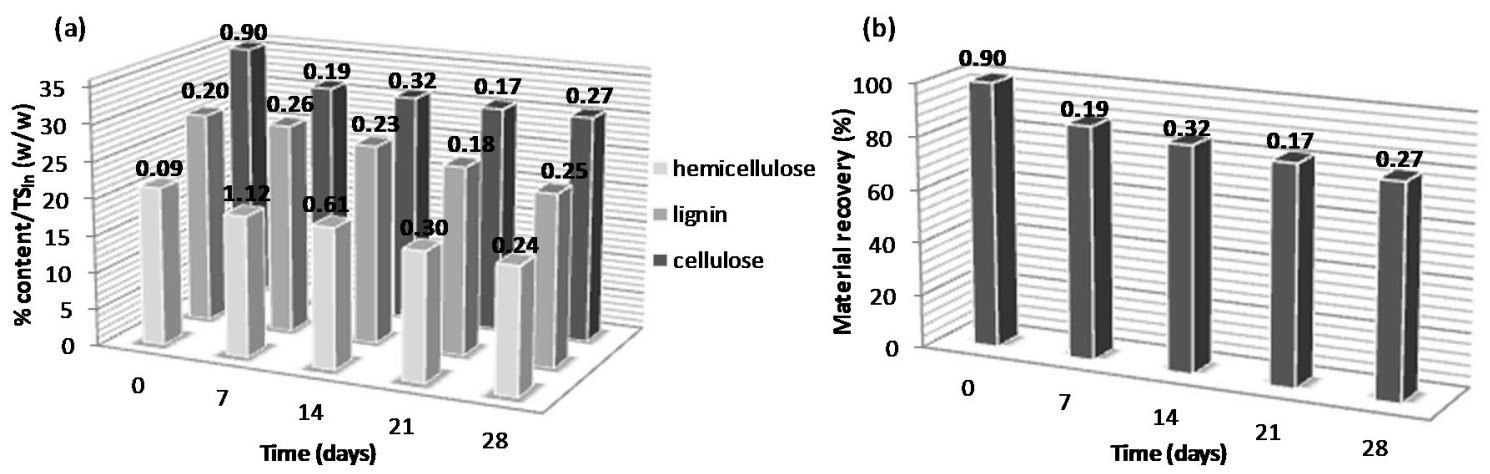

Figure 4. Changes in the relative ratios of: (a) lignin, cellulose, and hemicellulose to the initial total solids of WSD; and (b) material recovery, during fungal pretreatment with no addition of external nitrogen source (control). Numbers above the bars indicate the standard deviation of duplicates.

The relative changes on the lignocellulosic content and material recovery of pretreated WSD supplemented with nitrogen at 28 day compared to control (no external nitrogen addition) are summarized in Table 2 and were estimated according to the equation:

$$
R C=\frac{\mathrm{C}_{\text {control }}-\mathrm{C}_{\text {sample }}}{\mathrm{C}_{\text {control }}} \%
$$

where $R C$ is the relative change, i.e., increased or reduced content compared to control, $\mathrm{C}_{\text {control }}$ is the content of lignin, cellulose, hemicellulose, or material recovery of the control at 28 day of cultivation, and $\mathrm{C}_{\text {sample }}$ is the content of lignin, cellulose, hemicellulose, or material recovery of samples supplemented with nitrogen at 28 day of cultivation.

Table 2. Relative changes $(R C)$ on lignocellulosic content and material recovery of WSD after fungal pretreatment with $A$. biennis supplemented with nitrogen and compared to the respective ones of control cultures (no external $\mathrm{N}$ addition) after 28 days of cultivation. (YE: yeast extract, UR: urea, AN: ammonium nitrate).

\begin{tabular}{ccccc}
\hline N Source & $\boldsymbol{R C}$ of Lignin $^{\mathbf{1}} \mathbf{( \% )}$ & $\boldsymbol{R C}$ of Cellulose ${ }^{\mathbf{1}} \mathbf{( \% )}$ & $\boldsymbol{R C}$ of Hemicellulose ${ }^{\mathbf{1}} \mathbf{( \% )}$ & $\boldsymbol{R C}$ of Material Recovery ${ }^{\mathbf{1}} \mathbf{( \% )}$ \\
\hline YE high & $-0.97 \pm 0.16$ & $+36.25 \pm 2.05$ & $+0.52 \pm 0.05$ & $-0.12 \pm 0.01$ \\
YE low & $-1.77 \pm 0.26$ & $+10.41 \pm 1.66$ & $+1.66 \pm 0.23$ & $+1.93 \pm 0.22$ \\
UR high & $-21.61 \pm 2.06$ & $+3.63 \pm 0.38$ & $-13.23 \pm 1.97$ & $-9.32 \pm 1.38$ \\
UR low & $-1.82 \pm 0.28$ & $+6.47 \pm 1.00$ & $+8.52 \pm 1.41$ & $+2.57 \pm 0.35$ \\
AN high & $-2.43 \pm 0.34$ & $+16.15 \pm 1.09$ & $+5.28 \pm 0.81$ & $+4.84 \pm 1.01$ \\
AN low & $-4.19 \pm 0.78$ & $+7.43 \pm 0.99$ & $+4.28 \pm 0.61$ & $+4.08 \pm 0.58$ \\
\hline \multicolumn{5}{c}{ 1 expressed as relative $\%$ change versus control. }
\end{tabular}

As is obvious from the data presented at Table 2, the effect of nitrogen supplementation of fungal cultures on the delignification capacity of $A$. biennis was negligible in all cases, except for $\mathrm{UR}_{\text {high }}$, since it was reduced by less than $5 \%$ compared to the control. It seems that the addition of nitrogen, either in organic (YE, UR) or inorganic form (AN), does not enhance the ligninolytic efficiency of A. biennis, at least at the ratios of $\mathrm{N} / \mathrm{C}$ that were tested in the present study. On the contrary, the supplementation of WSD with a high concentration of urea $(20 \mathrm{mg} \mathrm{N} / \mathrm{gC})$ seems to actually inhibit delignification.

Contrary to the negligible effect of $\mathrm{N}$ addition on delignification, nitrogen supplementation during biological pretreatment of WSD exhibited a significant effect on cellulose degradation. As illustrated in Figures $1 b, 2 b$ and $3 b$, cellulose reduction during the cultivation period was, in all cases, enhanced by nitrogen addition, to a different extent though for each type and concentration of nitrogen source used. The most drastic effect on cellulose uptake was observed for the higher concentration of yeast extract $\left(\mathrm{YE}_{\text {high }}\right)$, followed by the higher concentration of ammonium nitrate $\left(\mathrm{AN}_{\text {high }}\right)$, whereas $\mathrm{UR}_{\text {high }}$ cultures were the least affected. Specifically, the final cellulose content at 28 day of cultivation reached 
$19.50 \% \pm 1.10 \%, 25.66 \% \pm 4.93 \%$, and $29.48 \% \pm 1.31 \%$ for $\mathrm{YE}_{\text {high }}, \mathrm{AN}_{\text {high }}$ and $\mathrm{UR}_{\text {high, }}$, respectively, with the initial cellulose content and the final content of control being $35.60 \% \pm 0.89 \%$ and $30.59 \% \pm 0.75 \%$, respectively. The relative change on cellulose uptake, as also shown in Table 2, was thus maximum for $\mathrm{YE}_{\text {high }}$ and minimal for $\mathrm{UR}_{\text {high. }}$. In general, higher $\mathrm{N} / \mathrm{C}$ ratios seem to lead to greater cellulose degradation regardless of the nitrogen source type, with the exception of $U_{\text {high }}$, for which the increase was marginal. In terms of type of nitrogen source used, YE and AN were shown to have the most severe effect.

As far as the hemicellulose uptake is concerned, as illustrated in Figures $1 c, 2 c$ and $3 c$ and Table 2, it was barely enhanced by nitrogen supplementation, with cultures supplemented with UR at low concentration $\left(\mathrm{UR}_{\mathrm{low}}\right)$ exhibiting the greater enhancement compared to control. In cultures supplemented with AN, the relative hemicellulose uptake was slightly increased compared to control for both $\mathrm{N} / \mathrm{C}$ ratios tested, whereas in cultures supplemented with YE, the degradation of hemicellulose was similar to that observed for control cultures. It is worth mentioning that, in the case of $\mathrm{UR}_{\text {high }}$ hemicellulose degradation was actually suppressed, exhibiting a relative reduction of $13.23 \% \pm 1.97 \%$ compared to the control experiment.

Material recovery (MR) represents the material, i.e., biomass and hydrolysate, that is reserved in the cultures. The reserved biomass includes the remaining WSD biomass, as well as the fungal biomass that is produced during biotransformation of WSD via incorporation of carbon and nutrients into the fungal body. The hydrolysate includes the monomeric compounds that are produced via the enzymatic activity of the fungus during the oxidation of lignin (phenols) and hydrolysis of complex carbohydrates (sugars), which remain in the aquatic phase of the culture. The MR during cultivation of A. biennis for different handlings is presented in Figures $1 \mathrm{~d}, 2 \mathrm{~d}, 3 \mathrm{~d}$ and $4 \mathrm{~d}$, whereas the content of the cultures in phenols and sugars at the end of cultivation is summarized in Table 3. Low MRs indicate high fungal metabolic activity via respiration and, thus, mineralization of the organic carbon towards $\mathrm{CO}_{2}$ with the consequent release of the latter in the atmosphere. During biological pretreatment of lignocellulosic biomass, a minimal loss of carbon is desirable. Moreover, depending on the final application of pretreated biomass, the conservation of carbon in the form of hydrolysates, rather than in the form of fungal biomass can be preferable. Thus, for applications, such as hydrogen and ethanol production which are mainly based on the bioconversion of sugars, the absence of significant sugars' degradation is crucial $[5,26]$, whereas in $\mathrm{AD}$, carbon even in the form of fungal biomass can also be acceptable, since most of the organic carbon can be eventually exploitable [6]. As shown in Table 2, the relative MR for all types of $\mathrm{N}$ and N/C ratios tested, except for $U R_{\text {high, }}$, is similar and actually MR is at the levels of control cultures (differences less than 5\%). Even in the case of $\mathrm{YE}_{\mathrm{high}}$, for which cellulose uptake was quite significant, MR is identical to control, thus indicating that carbon was actually used for growth rather than for maintenance via respiration. It is widely accepted that under nutrient stress conditions, more carbon is used for the production of energy via respiration than assimilated in the microbial biomass, not only in the case of basidiomycetes [27], but for other types of microorganisms as well [28].

Regarding the considerably higher MR of $\mathrm{UR}_{\text {high }}$ cultures compared to control, it is assumed that it is not due to the assimilation in the fungal biomass, but actually due to minimal fungal activity. Indeed, the observed suppression of hemicellulose uptake and the minimum cellulose uptake compared to control during supplementation with UR at high N/C ratio, indicates that the inhibition on delignification was actually due to growth inhibition. This assumption is further supported by the increased amount of phenolics that were detected in those cultures after 28 day of cultivation (Table 3) that was $100 \%$ higher than in all other cases, which are assumed to accumulate rather than be consumed due to low activity of the fungus. Allison et al. [29] have reported that during decomposition experiments of different hardwoods supplemented with 20 or $200 \mu \mathrm{g} \mathrm{N}$ per $200 \mathrm{mg}$ of substrate in the form of AN, using the basidiomycetes Pholiota carbonaria and Agrocybe praecox, mineralization of the substrates was enhanced for the lower N/C contents compared to control, but it is significant only for those substrates that had extremely low initial N concentrations. WSD is also categorized 
as a hardwood with a low N/C ratio, but in our case mineralization did not seem to be enhanced by the lower $\mathrm{N}$ addition. It has to be mentioned, though, that both ratios of $\mathrm{N} / \mathrm{C}$ used in the present study were higher than $20 \mu \mathrm{g} \mathrm{N} / 200 \mathrm{mg}$ of substrate and actually the lowest ratio used $(4 \mathrm{mg} / \mathrm{g} \cdot \mathrm{C})$ is comparable to the higher ratio used by Allison et al. [29], whereas there was no significant effect. As far as the effect of AN on the decomposition of lignin is concerned, in the study of Allison et al. [29] there was no significant effect for both ratios tested compared to the control, which is consistent with the findings of the present study. D'Agostini et al. [30] have examined the effect of different $\mathrm{C} / \mathrm{N}$ ratios (5-30, corresponding to $\sim 100 \mathrm{mg} \cdot \mathrm{N} / \mathrm{g} \cdot \mathrm{C}-16 \mathrm{mg} \cdot \mathrm{N} / \mathrm{g} \cdot \mathrm{C}$ ) in lacasse production, during growth of three different basidiomycetes, Pleurotus ostreatus, Lentinula edodes, and Agaricus blazei on soybean hulls, by adding $\mathrm{N}$ in the form of $\mathrm{AN}$ and/or UR. It was shown that higher $\mathrm{C} / \mathrm{N}$ ratios, i.e., lower $\mathrm{N} / \mathrm{C}$ ratios, increased mycelial growth, but decreased laccase production. Nevertheless, those effects are not correlated with the mineralization of organic carbon or delignification efficiency.

Table 3. Phenolic and sugar content in the hydrolysates of fungi-pretreated samples of WSD, supplemented with different $\mathrm{N}$ sources at high and low concentrations (YE: yeast extract, UR: urea, AN: ammonium nitrate).

\begin{tabular}{ccc}
\hline N Source & Phenols $\left(\mathbf{m g} / \mathbf{g T S}_{\mathbf{i n}}\right)$ & Sugars $\left(\mathbf{m g} / \mathbf{g T S}_{\mathbf{i n}}\right)$ \\
\hline None (control) & $2.92 \pm 0.12$ & $22.60 \pm 0.96$ \\
YE high & $4.29 \pm 0.18$ & $27.56 \pm 2.01$ \\
YE low & $3.94 \pm 0.07$ & $27.17 \pm 1.34$ \\
UR high & $7.37 \pm 0.13$ & $11.50 \pm 0.91$ \\
UR low & $3.54 \pm 0.15$ & $24.08 \pm 1.05$ \\
AN high & $3.46 \pm 0.11$ & $37.60 \pm 2.74$ \\
AN low & $3.16 \pm 0.11$ & $27.02 \pm 1.89$ \\
\hline
\end{tabular}

\subsection{Effect of Alkaline Pretreatment on the Lignocellulosic Content of Biologically Pretreated WSD}

Following the protocol that was used in the study of Alexandropoulou et al. [6], the biologically pretreated WSD after 28 days of cultivation was further subjected to alkali pre-treatment by adding $\mathrm{NaOH} 20 \% w / w$ dry mass, at $80^{\circ} \mathrm{C}$ for $24 \mathrm{~h}$. In Figure 5 a, the content of the WSD in lignin, cellulose, and hemicellulose, after combined pretreatment, is presented. For all three parameters, values were expressed on the basis of the initial TS of WSD that was used before biological pretreatment. Thus, material recovery was actually accounted for in the final values presented. In Figure $5 \mathrm{~b}$ material recovery after the combined pretreatment is given.

Alkali pretreatment using $\mathrm{NaOH}$ is one of the most common pretreatment methods. It has been extensively studied and applied for the fractionation of lignocellulosic biomass and its further bioconversion towards energy carriers and different high added-value products [3]. Indeed, $\mathrm{NaOH}$ treatment is reported to be highly effective in increasing the digestibility of softwood [4], as well as hardwood [26]. Pretreatment of lignocellulose with $\mathrm{NaOH}$ increases the internal surface by swelling, decreases the degree of polymerization and crystallinity, disrupts the links between lignin and other polymers, and causes the lignin to break down [3]. Lignin is particularly affected by $\mathrm{NaOH}$. In particular, alkali addition causes depolymerisation and cleavage of the lignin-carbohydrate linkages. Hemicellulose solubilisation into its oligomers also takes place, though to a quite smaller degree compared to that caused by acid pretreatment, whereas the cellulose structure is affected to a lesser degree. The effectiveness of alkali pretreatment depends on the lignin content of the biomass. In general, substrates with lower lignin content seem to be more vulnerable to chemical attack. Thus, the effect of $\mathrm{NaOH}$ treatment on a substrate that is already partly delignified, such as a prior biologically pretreated substrate would be expected to be severe. The above are indeed verified by the results of the present study, as presented in Table 4 . 
(a)

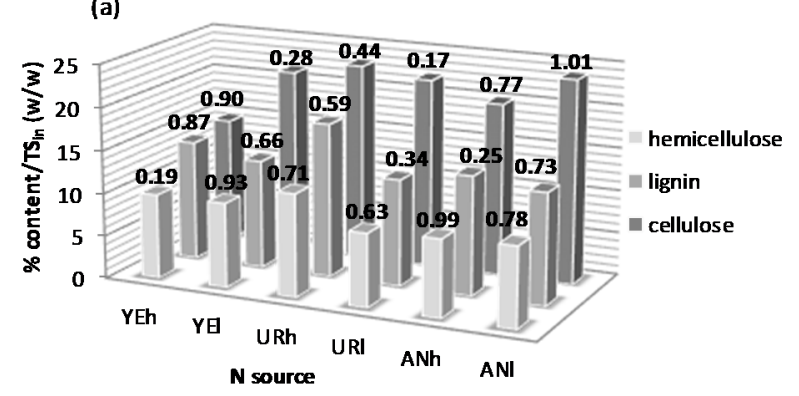

(b)

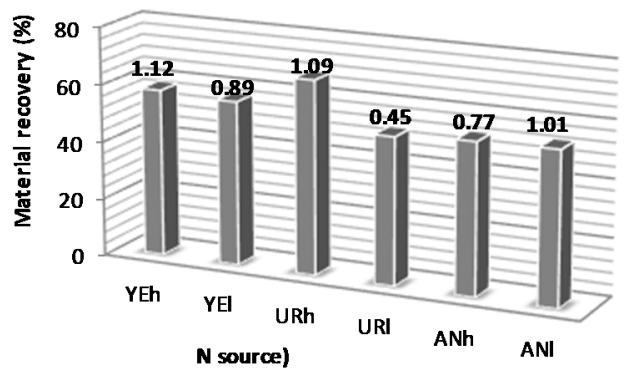

Figure 5. Changes in the relative ratios of: (a) lignin, cellulose, and hemicellulose to the initial total solids of WSD; and (b) material recovery, after combined fungal pretreatment with addition of external nitrogen sources and alkaline pretreatment. Numbers above the bars indicate the standard deviation of duplicates. Abbreviations: YEh, yeast extract high N/C ratio; YEl, yeast extract low N/C ratio; $\mathrm{URh}$, urea high N/C ratio; URl, urea low N/C ratio; $\mathrm{ANh}$, ammonium nitrate high $\mathrm{N} / \mathrm{C}$ ratio; and $\mathrm{ANl}$, ammonium nitrate low $\mathrm{N} / \mathrm{C}$ ratio.

Table 4. Relative changes on lignocellulosic content and material recovery of WSD after alkali pretreatment of biologically pretreated samples after 28 days of cultivation, with $\mathrm{N}$ supplementation.

\begin{tabular}{|c|c|c|c|c|}
\hline N Source & $R C$ of $\operatorname{Lignin}^{1}(\%)$ & RC of Cellulose ${ }^{1}(\%)$ & RC of Hemicellulose ${ }^{1}(\%)$ & $R C$ of Material Recovery ${ }^{1}(\%)$ \\
\hline YE high & $-50.60 \pm 3.12$ & $-24.78 \pm 2.45$ & $-42.45 \pm 0.90$ & $-29.26 \pm 3.43$ \\
\hline YE low & $-51.51 \pm 2.45$ & $-21.96 \pm 3.99$ & $-41.34 \pm 3.65$ & $-29.06 \pm 1.09$ \\
\hline UR high & $-46.58 \pm 5.56$ & $-22.21 \pm 2.48$ & $-38.12 \pm 2.62$ & $-24.66 \pm 2.74$ \\
\hline UR low & $-54.50 \pm 3.22$ & $-22.84 \pm 4.01$ & $-43.29 \pm 3.21$ & $-31.04 \pm 4.18$ \\
\hline AN high & $-53.81 \pm 1.89$ & $-21.63 \pm 5.32$ & $-44.41 \pm 4.02$ & $-28.90 \pm 0.93$ \\
\hline AN low & $-55.42 \pm 4.00$ & $-18.85 \pm 3.45$ & $-42.98 \pm 3.99$ & $-30.21 \pm 1.11$ \\
\hline
\end{tabular}

${ }^{1}$ expressed as relative \% change versus the respective biologically pretreated sample.

By comparing Figure 5 with Figures 1 and 3, it can be deduced that, in all cases, alkali pretreatment had a significant effect on the lignocellulotic content of the biologically pretreated WSD, exhibiting a considerable loss of lignin, cellulose, and hemicellulose. Moreover, it seems that in all cases, regardless of the type of the $\mathrm{N}$ source and the $\mathrm{N} / \mathrm{C}$ ratio during prior fungal pretreatment, the effect on lignin and carbohydrate reduction seems to be proportional, and actually comparable, to the respective reductions that were noticed in our previous study [6]. These changes become more obvious when expressed in terms of relative reduction. In Table 4 the relative changes on the content of lignin, cellulose, and hemicellulose as well on the material recovery of the alkaline pretreated samples after of 28 day cultivation with $A$. biennis are summarized. It is apparent that primarily lignin is attacked by $\mathrm{NaOH}$, followed by hemicellulose and cellulose, which are solubilized as previously reported [6]. The solubilization of lignin and holocellulose is also reflected in the estimated material recovery of combined pretreated WSD samples, which is considerably lower than that of the respective samples after solely fungal pretreatment.

\subsection{Methanogenic Potential of Fungi and Combined Fungi/Alkali Pretreated WSD}

In Figure 6a, the results of the BMP experiments of the fungi-pretreated WSD after 28 day of cultivation without (control) and with external $\mathrm{N}$ supplementation (YE, UR, AN) at high and low $\mathrm{N} / \mathrm{C}$ ratios, as well as the respective samples after combined fungi and alkali pretreatment (Figure 6b), are presented. For comparison purposes, the BMP of the WSD and that of alkali-pretreated WSD, were also assessed. It should be noted that the values in Figure 6 are expressed per $\mathrm{TS}_{\text {in }}$, taking into account the solid material recovery of biomass during pretreatment. The biological methane potential of WSD was $95.32 \pm 7.59 \mathrm{~L} \cdot \mathrm{CH}_{4} / \mathrm{kg}$ TS, similar to that found in other studies, where willow was used as feedstock $[6,31]$. 
It can be seen that the methane potential after biological pretreatment with $A$. biennis without $\mathrm{N}$ supplementation increased, resulting in a BMP increase of $47.88 \%\left(140.96 \pm 0.33 \mathrm{~L} \cdot \mathrm{CH}_{4} / \mathrm{kg}\right.$ TS $)$ compared to the respective of untreated WSD. This could be attributed to the high delignification efficiency of $A$. biennis accompanied by a low holocelluloses uptake during the control experiment. The results are comparable to our previous study, where A. biennis exhibited a BMP increase of $43 \%$ due to its high lignin selectivity against cellulose [6]. A positive effect on BMP was reported by other studies, i.e., a 120\% increase on the methane yield of Agropyron elongatum "BAMAR" pretreated with Flammulina velutipes [32] or $25 \%$ increase of the specific methane yield of miscanthus harvested in the spring, pretreated with Ceriporiopsis subvermispora [33].
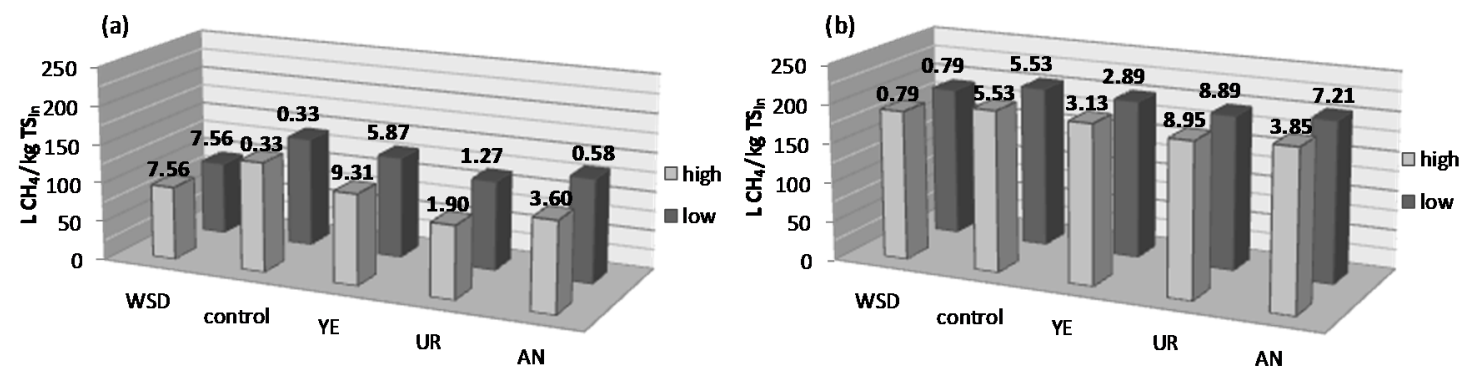

Figure 6. Methane generation of WSD after fungal pretreatment with addition of external nitrogen sources at high and low $\mathrm{N}$ concentration (a) and combined fungal/alkaline pretreatment (b). Numbers above the bars indicate the standard deviation of duplicates. (YE: yeast extract, UR: urea, AN: ammonium nitrate).

On the other side, $\mathrm{N}$ supplement, regardless of the external $\mathrm{N}$ source resulted in a reduction of the methane yield, compared to the control experiment. Especially, in the case of YE or AN, the high N/C ratio led to lower BMP, compared with the respective at low N/C ratio $(20.91 \%$ and $7.71 \%$ reduction for $\mathrm{YE}_{\text {high }}$ and $\mathrm{YE}_{\text {low }}$ compared to the control experiment and $21.68 \%$ and $5.53 \%$ reduction for $\mathrm{AN}_{\text {high }}$ and $\mathrm{AN}_{\text {low }}$, respectively). The higher BMP yields for low $\mathrm{N} / \mathrm{C}$ ratios, could be attributed to the lower cellulose uptake, which was carried out under these conditions. Based on Table 2, the relative changes of cellulose was $36.25 \% \pm 2.05 \%$ and $16.15 \% \pm 1.09 \%$ for $\mathrm{YE}$ and $\mathrm{AN}$ at high N/C ratio compared to the control experiment, while the respective values were $10.41 \% \pm 1.66 \%$ and $7.43 \% \pm 0.99 \%$ for YE and $\mathrm{AN}$ at low $\mathrm{N} / \mathrm{C}$ ratios. This indicates that selective delignification in terms of the ratio of lignin to cellulose, leads to higher methane yields, as also reported by other studies [2,6].

In the case of urea addition at high N/C ratio, the decrease in the BMP yield was much higher $(50.86 \%)$ compared to the control experiment, corresponding to $93.44 \pm 1.90 \mathrm{~L} \cdot \mathrm{CH}_{4} / \mathrm{kg}$ TS, a value similar to the respective raw untreated WSD $\left(95.32 \pm 7.59 \mathrm{~L} \cdot \mathrm{CH}_{4} / \mathrm{kg}\right.$ TS). At such high UR concentration, the delignification efficiency of $A$. biennis was negligible and the material recovery of WSD was very high, indicating that the fungal growth was inhibited and, thus, the fungal pretreatment with UR at high N/C had no impact on BMP of WSD.

The lower BMP yields obtained in all fungal pretreatment methods with $\mathrm{N}$ supplementation (except from $\mathrm{UR}_{\text {high }}$ ) could be attributed to the higher cellulose uptake, which was achieved, compared to the control experiment. The fact that the material recovery was similar, respective of the control, indicates that the carbon content of cellulose was preserved in the culture but was not accessible to hydrolytic enzymes so that it could be converted to biogas. These results indicate that the effect of fungal pretreatment on methane yield strongly depends on the key operational parameters, such as nutrient supplementation since these parameters affect lignolytic enzymes production, delignification efficiency, and holocelluloses uptake [2].

Alkali pretreated WSD exhibited a methane potential of $190.13 \pm 7.53 \mathrm{~L} \cdot \mathrm{CH}_{4} / \mathrm{kg}$ TS which was $99.4 \%$ higher than the respective untreated WSD. The increase in methane yield was anticipated and could be attributed to the high lignin reduction which occurred through alkali addition, which is 
correlated to the BMP yield. The lower the lignin content in a lignocellulosic substrate, the higher was the methane potential of the specific substrate [3,34].

The combination of biological and alkali pretreatment enhanced the BMP of WSD to a value of $204.32 \pm 0.33 \mathrm{~L} \cdot \mathrm{CH}_{4} / \mathrm{kg}$ TS (control). This was probably due to an improved accessibility to cellulose, since during fungal pretreatment the removal of hemicellulose and lignin was facilitated, while during alkali pretreatment, a fractionation took place and, thus, a synergistic effect occurred on cellulose digestibility [35]. Thus, the BMP of combined treatment was $7.46 \%$ and $34.88 \%$ higher than the respective alkali or fungi pretreatment alone. In addition, the combination of two different pretreatment steps led to a $116.61 \%$ increase of BMP compared to the raw WSD.

Similar BMP yields were observed for all experiments with N supplementation (Figure $6 \mathrm{~b}$ ) indicating that a high contribution for the BMP increase was due to alkaline treatment, since fungi pretreatment alone, under $\mathrm{N}$ supplementation, had a negative impact on BMP. It is assumed that under alkaline conditions, the carbon content of holocelluloses, which was preserved in the culture during $\mathrm{N}$ supplementation, was fractionated, becoming accessible to hydrolytic enzymes of mixed anaerobic cultures, thus facilitating methane generation. In that respect, a combination of fungi with alkali pretreatment enhanced methane production compared to alkali or fungi pretreatment alone, while supplementation of nitrogen at all N/C ratios did not contribute to the methane yield compared to the combined fungal and alkaline pretreatment without $\mathrm{N}$ supplementation (control experiment).

Based on the findings of this study, it can be assumed that fungi pretreatment, itself, without $\mathrm{N}$ supplementation can indeed lead to improved methane yields from WSD, since an increase of $47.88 \%$ was observed (compared to the untreated WSD). A further increase in methane potential was recorded when additional pretreatment via alkali was applied (116\% increase compared to the untreated WSD). At a first glance, it could be assumed that combined pretreatment led to much more impressive results. Taking, however, into consideration the use of chemicals, the higher temperatures required (from $30^{\circ} \mathrm{C}$ during biological pretreatment to $80^{\circ} \mathrm{C}$ during alkaline pretreatment), as well as the requirement for specialized equipment resistant to corrosion, the combined pretreatment could not be as appealing as it seems. On the other hand, comparing the direct application of $\mathrm{NaOH}$ to the combined fungal/alkaline pretreatment, the enhancement of methane yields is less significant since it is obvious that only a $7.46 \%$ increase was observed. Thus, despite the possible drawbacks of alkali pretreatment, the prolonged cultivation times that are required for fungal treatment might also be disadvantageous for the viability of the overall combined process. In order to come to a solid conclusion for the practical application of each methodology proposed and their combinations, it is apparent that all of the above parameters should be taken onto account in a detailed sustainability/techno-economical analysis. What should be noted, however, is that some kind of pretreatment is certainly required in order to improve the digestibility of the selective substrate which, when untreated, led to poor methane potential.

\section{Conclusions}

Biological fungal pretreatment of WSD with A. biennis with different $\mathrm{N}$ sources did not facilitate delignification, regardless of the type of nitrogen source and the ratio of $\mathrm{N} / \mathrm{C}$ used. On the other hand, a significant effect on cellulose degradation was observed, indicating that $\mathrm{N}$ supplementation did not enhance fungal pretreatment. For the case of urea addition at high $\mathrm{N}$ concentration, an inhibition on delignification was observed, which was attributed to fungal growth inhibition. A combination of fungal with alkali pretreatment led to high lignin and holocellulose degradation, which was mainly due to the alkali pretreatment. Biological pretreatment with $A$. biennis without $\mathrm{N}$ supplementation (control) improved the BMP of WSD by $47.88 \%$. In the case of external $\mathrm{N}$ addition, the BMP was reduced compared to the control, which could be attributed to the higher cellulose uptake that was achieved. The combination of alkaline with biological pretreatment enhanced the BMP of WSD and was $7.46 \%$ and $34.88 \%$ higher than the respective alkaline or fungal pretreatment alone. In addition, the combination of two different pretreatment steps led to a $116.61 \%$ increase of BMP compared to the raw WSD. The fact that BMP yields for all experiments with $\mathrm{N}$ supplementation were similar to the 
control (combined fungal and alkali pretreatment without $\mathrm{N}$ supplementation) indicates that a high contribution for the BMP increase was due to alkaline treatment, through which the carbon content of holocelluloses which was preserved in the culture, was fractionated, thus facilitating enzymatic hydrolysis and methanogenesis.

Acknowledgments: The authors wish to thank the Greek General Secretariat for Research and Technology for the financial support of this work through "Bilateral projects Greece-France 2013-2015-Francellas-1455 project" as well as Leonidas Jonuzaj for kindly supply of WSD.

Author Contributions: Georgia Antonopoulou, Ioanna Ntaikou and Gerasimos Lyberatos conceived and designed the experiments; Maria Alexandropoulou performed the experiments; Georgia Antonopoulou analyzed the data; Georgia Antonopoulou and Ioanna Ntaikou wrote the paper.

Conflicts of Interest: The authors declare no conflict of interest.

\section{References}

1. Börjesson, P.; Mattiasson, B. Biogas as a resource-efficient vehicle fuel. Trends Biotechnol. 2008, 26, 7-13. [CrossRef] [PubMed]

2. Rouches, E.; Herpoël-Gimbert, I.; Steyer, J.P.; Carrere, H. Improvement of anaerobic degradation by white-rot fungi pretreatment of lignocellulosic biomass: A review. Renew. Sustain. Energy Rev. 2016, 59, 179-198. [CrossRef]

3. Carrere, H.; Antonopoulou, G.; Passos, F.; Affes, R.; Battimelli, A.; Lyberatos, G.; Ferrer, I. Review of pretreatment strategies for the most common anaerobic digestion feedstocks: From lab-scale research to full-scale application. Bioresour. Technol. 2016, 199, 386-397. [CrossRef] [PubMed]

4. Antonopoulou, G.; Dimitrellos, G.; Beobide, A.S.; Vayenas, D.; Lyberatos, G. Chemical pretreatment of sunflower straw biomass: The effect on chemical composition and structural changes. Waste Biomass Valoriz. 2015, 6, 733-746. [CrossRef]

5. Antonopoulou, G.; Dimitrellos, G.; Beobide, A.S.; Vayenas, D.; Lyberatos, G. Ethanol and hydrogen production from sunflower straw: The effect of pretreatment on the whole slurry fermentation. Biochem. Eng. J. 2016, 116, 65-74. [CrossRef]

6. Alexandropoulou, M.; Antonopoulou, G.; Fragkou, E.; Ntaikou, I.; Lyberatos, G. Fungal pretreatment of willow sawdust and its combination with alkaline treatment for enhancing biogas production. J. Environ. Manag. 2016. [CrossRef] [PubMed]

7. Tuor, U.; Winterhalter, K.; Fiechter, A. Enzymes of white-rot fungi involved in lignin degradation and ecological determinants for wood decay. J. Biotechnol. 1995, 41, 1-17. [CrossRef]

8. Dashtban, M.; Schraft, H.; Syed, T.A.; Qin, W. Fungal biodegradation and enzymatic modification of lignin. Int. J. Biochem. Mol. Biol. 2010, 1, 36-50. [PubMed]

9. Amirta, R.; Tanabe, T.; Watanabe, T.; Honda, Y.; Kuwahara, M.; Watanabe, T. Methane fermentation of Japanese cedar wood pretreated with a white rot fungus Ceriporiopsis subvermispora. J. Biotechnol. 2006, 123, 71-77. [CrossRef] [PubMed]

10. Feng, X.; Castillo, M.D.P.; Schnürer, A. Fungal Pretreatment of Straw for Enhanced Biogas Yield; Report No. 2013:279; Swedish Gas Technology Centre: Malmo, Sweden, 2013.

11. Wan, C.; Li, Y. Fungal pretreatment of lignocellulosic biomass. Biotechnol. Adv. 2012, 30, 1447-1457. [CrossRef] [PubMed]

12. Sindhu, R.; Binod, P.; Pandey, A. Biological pretreatment of lignocellulosic biomass: An overview. Bioresour. Technol. 2016, 199, 76-82. [CrossRef] [PubMed]

13. Galhaup, C.; Wagner, H.; Hinterstoisser, B.; Haltrich, D. Increased production of laccase by the wood-degrading basidiomycete Trametes pubescens. Enzym. Microb. Technol. 2002, 3, 529-536. [CrossRef]

14. Buswell, J.A.; Cai, Y.J.; Chang, S.-T. Effect of nutrient nitrogen and manganese on manganese-peroxidase and laccase production of Lentinula (Lentinus) edodes. FEMS Microbiol. Lett. 1995, 128, 81-88. [CrossRef]

15. Isroi; Millati, R.; Syamsiah, S.; Niklasson, C.; Cahyanto, M.N.; Lundquist, K.; Taherzadeh, M.J. Biological pretreatment of lignocelluloses with white-rot fungi and its applications: A review. Bioresources 2011, 6, 5224-5259.

16. Mikiashvili, N.; Wasser, S.; Nevo, E.; Elisashvili, V. Effects of carbon and nitrogen sources on Pleurotus ostreatus ligninolytic enzyme activity. World J. Microbiol. Biotechnol. 2006, 22, 999-1002. [CrossRef] 
17. Sarkar, N.; Ghosh, S.K.; Bannerjee, S.; Aikat, K. Bioethanol production from agricultural wastes: An overview. Renew. Energy 2012, 37, 19-27. [CrossRef]

18. Shirkavand, E.; Baroutian, S.; Gapes, D.J.; Young, B.R. Combination of fungal and physicochemical processes for lignocellulosic biomass pretreatment-A review. Renew. Sustain. Energy Rev. 2016, 54, 217-234. [CrossRef]

19. Owens, J.M.; Chynoweth, D.P. Biochemical methane potential of municipal solid waste (MSW) components. Water Sci. Technol. 1993, 27, 1-14.

20. Skiadas, I.V.; Lyberatos, G. The periodic anaerobic baffled reactor. Water Sci. Technol. 1998, 38, 401-408. [CrossRef]

21. Sluiter, A.; Ruiz, R.; Scarlata, C.; Sluiter, J.; Templeton, D. Determination of Extractives in Biomass: Laboratory Analytical Procedure; National Renewable Energy Laboratory: Golden, CO, USA, 2008.

22. Sluiter, A.; Hames, B.; Ruiz, R.; Scarlata, C.; Sluiter, J.; Templeton, D.; Crocker, D. Determination of Structural Carbohydrates and Lignin in Biomass: Laboratory Analytical Procedure; National Renewable Energy Laboratory: Golden, CO, USA, 2008.

23. Joseffson, B. Rapid spectrophotometric determination of total carbohydrates. In Methods of Seawater Analysis; Grasshoff, K., Ehrhardt, M., Kremling, K., Eds.; Verlag Chemie GmbH: Weinheim, Germany, 1983; pp. 340-342.

24. Waterman, P.G.; Mole, S. Analysis of phenolic plant metabolites. In Methods in Ecology; Lawton, J.H., Likens, G.E., Eds.; Oxford Blackwell Scientific Publications: London, UK, 1994.

25. American Public Health Association; American Water Works Association; Water Environment Federation. Standard Methods for the Examination of Water and Wastewater; Franson, M.A., Ed.; American Public Health Association: Washington, DC, USA, 1995.

26. Senkevich, S.; Ntaikou, I.; Lyberatos, G. Bioethanol production from thermochemically pre-treated olive mill solid residues using the yeast Pachysolen tannophilus. Glob. Nest J. 2012, 14, 118-124.

27. Watkinson, S.; Bebber, D.; Darrah, P.; Fricker, M.; Tlalka, M.; Bodd, L. The role of wood decay fungi in the carbon and nitrogen dynamics of the forest floor. In Fungi in Biogeochemical Cycles; Gadd, G.M., Ed.; Cambridge University Press: New York, NY, USA, 2006.

28. Touratier, F.; Legendre, L.; Vezina, A. Model of bacterial growth influenced by substrate C:N ratio and concentration. Aquat. Microb. Ecol. 1999, 19, 105-118. [CrossRef]

29. Allison, S.D.; LeBauer, D.S.; Ofrecio, M.R.; Reyes, R.; Ta, A.-M.; Tran, T.M. Low levels of nitrogen addition stimulate decomposition by boreal forest fungi. Soil Biol. Biochem. 2009, 41, 293-302. [CrossRef]

30. D'Agostini, E.C.; Mantovani, T.R.D.; do Valle, J.S.; Paccola-Meirelles, L.D.; Colauto, N.B.; Linde, G.A. Low carbon/nitrogen ratio increases laccase production from basidiomycetes in solid substrate cultivation. Sci. Agric. 2011, 68, 295-300.

31. Jurado, E.; Gavala, H.N.; Skiadas, I.V. Enhancement of methane yield from wheat straw, miscanthus and willow using aqueous ammonia soaking. Environ. Technol. 2013, 34, 2069-2075. [CrossRef] [PubMed]

32. Lalak, J.; Kasprzycka, A.; Martyniak, D.; Tys, J. Effect of biological pretreatment of Agropyronelongatum "BAMAR" on biogas production by anaerobic digestion. Bioresour. Technol. 2016, 200, 194-200. [CrossRef] [PubMed]

33. Vasco-Correa, J.; Li, Y. Solid-state anaerobic digestion of fungal pretreated Miscanthus sinensis harvested in two different seasons. Bioresour. Technol. 2015, 185, 211-217. [CrossRef] [PubMed]

34. Monlau, F.; Sambusiti, C.; Barakat, A.; Guo, X.M.; Latrille, E.; Trably, E.; Steyer, J.P.; Carrère, H. Predictive models of biohydrogen and biomethane production based on the compositional and structural features of lignocellulosic materials. Environ. Sci. Technol. 2012, 46, 12217-12225. [CrossRef] [PubMed]

35. Yang, H.; Wang, K.; Wang, W.; Sun, R.-C. Improved bioconversion of poplar by synergistic treatments with white-rot fungus Trametes velutina D10149 pretreatment and alkaline fractionation. Bioresour. Technol. 2013, 130, 578-583. [CrossRef] [PubMed]

(C) 2017 by the authors; licensee MDPI, Basel, Switzerland. This article is an open access article distributed under the terms and conditions of the Creative Commons Attribution (CC-BY) license (http:/ / creativecommons.org/licenses/by/4.0/). 